\title{
DEVELOPING THE VOICE OF A HISTORIAN IN FRENCH-MEDIUM CLIL HISTORY COURSES: A STUDY AMONG FLEMISH ADOLESCENTS
}

\author{
Lies Sercu \\ Prof. Dr., Katholieke Universiteit Leuven (KU Leuven), Belgium, lies.sercu@kuleuven.be \\ ORCID 0000-0003-3213-396X
}

\begin{abstract}
More and more Flemish pupils are taking history courses in a foreign language. In that school subject, pupils develop historical insight and learn to report on historical events, their possible interpretations and the importance of those events for the further course of history in the CLIL-language. This study examined the extent to which CLIL and non-CLIL pupils from the second grade of secondary education (15-year-olds) can express this historical view ("the voice of the historian") in a French-medium written text in the context of history lessons. Two Flemish CLIL classes and one non-CLIL class were given an essay question containing three types of questions that historians usually ask themselves: 'what are the objective facts?', 'How can I interpret those facts?', 'How do I estimate the importance of the events?'. These questions were answered with respect to contents relating to the Great Voyages of Discovery and Reformation and Counter Reformation.
\end{abstract}

A qualitative interpretative linguistic-semiotic discourse analytic approach, inspired by Halliday's Systemic Functional Linguistic Framework (Halliday \& Mathiessen, 2014) and Martin \& White's (2005) 'evaluative language' framework, was used to analyze the data. Thus, our analysis involved checking whether the learners were able to realize the textual, interpersonal and ideational functions of written discourse in the CLIL-language (French) using a neutral, non-graduating register.

The results based on an analysis of 36 essays show that students of that age can produce a coherent text in answer to the set essay questions and demonstrate the ability to use the voice of the historian within an educational context. Thus, they are able to address the three elements of the voice of the historian (facts, interpretations, importance) in their texts, at least at a level that can be expected of 15-year-olds. CLIL learners appear to be able to do this slightly better than non-CLIL learners. On the other hand, non-CLIL learners are able to realize the textual dimension, as defined within the SFL framework, somewhat better than CLIL learners, noting especially that CLIL learners use a somewhat more subjective, more graduating style, than non-CLIL learners. Overall, however, CLIL learners' texts score $5 \%$ higher than those of non-CLIL learners.

This small-scale qualitative study on students' ability to write as historians in a foreign language within the context of CLIL-education demonstrates that the knowledge, skills and ways of reasoning to be acquired within history education can be acquired equally well, if not better, in CLIL-classes as in non-CLIL-classes. Awareness and understanding of the linguistic demands involved in the acquisition of the ability to realize the textual, ideational and interpersonal functions of historical reports in a foreign language may constitute an important step in further professionalizing CLIL-teachers. We hope our research may inform policy makers and teacher educators about the need to educate CLIL-teachers in this respect, ultimately to improve the quality of all CLIL education.

Keywords: adolescent mastery of contents and language in CLIL education, voice of the historian, systemic functional discourse analysis, appraisal language. 


\section{INTRODUCTION}

In Content-and-Language-Integrated (CLIL) education, a school subject is taught in a foreign language and the foreign language is taught through the subject. Within this integrative conceptualisation, students are expected to produce subject-specific discourse in the CLIL-language. Discourse, then, does not merely refer to their ability to use specific lexical items in correct grammatical sentences while talking about subject matter. It also implies mastery of the characteristics of specific text genres commonly used within a certain scientific discipline (Council of Europe, 2016). "Genre" refers to a type of communication that is based on socially agreed upon conventions. These conventions may concern the selection of topics, but also organizational, content related or linguistic and stylistic features. Importantly, genres may be neutral in tone, but may also aim to manipulate the reader, promoting the authors' attitude towards the topic, their ideological convictions, or their appraisal of particular events.

The study reported here aimed to investigate to what extent 15-year-old Flemish students in general secondary education taking a CLIL history course in French are able to use the voice of a historian when writing a composition in French in answer to an exam question touching upon subject matter covered in the classroom. Using this voice implies the ability to observe the conventions of the historical report, using an objectifying academic style to describe and narrate historical events and reflect on their meaning for today's society.

Contrary to much of the CLIL-research to date (Pavon Vazquez, 2018), this study does not focus on studying students' acquisition of subject-specific vocabulary and grammar only. Rather, it centres on the mastery of the ways of expression used by professionals within a certain scientific field. Through the analysis of student French-medium essays written in answer to exam prompts, we were able to show that, to varying degrees, CLIL students are able to use the voice of the historian in the foreign language, but that their non-CLIL counterparts can do so in a slightly more objective way as they master their mother tongue at a higher level than the CLIL-students master the CLIL-language. Yet, overall CLIL-students slightly outperform non-CLIL students with respect to other assessment criteria related to the expression of the voice of the historian. The essays were analysed within Halliday \& Matthiessen's (2004) Systemic Functional Linguistic (SFL) and Martin \& White's (2005) 'language of evaluation' framework. They are posited against the background of what is expected of 15-year-old learners in Flemish secondary education with respect to the acquisition of written communication skills in Dutch and in French, and of historical skills.

\section{BACKGROUND}

\subsection{Students' Learning Task in CLIL History-French}

To determine what level of mastery of historical thinking as expressed in writing we can expect of 15-yearolds in Flanders (Belgium), we mapped the curricular attainment targets for history, writing in the mother tongue (Dutch) and writing in French for this age group.

\subsubsection{Becoming a historian at school: what we expect of 15-year-old adolescents}

As regards history, the Flemish curricular documents in point are comparable to British Key stage 3 attainment target documents (Department of Education, 2013). Students are developing towards "deepening their understanding of the people, periods and events studied" and are enabled "to think critically, weigh evidence, sift arguments, make informed decisions and develop perspective and judgement." (Ofqual, 2020, p. 3). Indeed, the participants in our study are expected to be able to demonstrate an understanding of historical events, an ability to use historical language and concepts and the skills to assess the value of historical documents for arriving at a multiperspectival and truthful view of historical events. (VVSKO, 1999, pp. 15-16). Students can place their growing knowledge of important historical concepts, such as expansion, dissolution, civilization, cause and consequence, continuity and change, etc., into different contexts, understanding the dynamic interplay between local, national and international forces, and discovering connections between different societal domains. They can summarize historical findings and name the focal point. Additionally, they can compare societies with respect to similarities and differences and illustrate which societal domains are interfering. They can formulate hypotheses regarding the meaning of a historical event and can test those hypotheses (p. 16). In other words, students are not yet expected to be able to fully interpret historical events or judge them as historians would do. It is only at GCSE-level that young adults are to "engage in historical enquiry to develop as independent learners and as critical and reflective thinkers (...) and to organize and communicate their historical knowledge and understanding in different ways and reach substantiated conclusions." (Ofqual, 2020, p. 3)

In sum, in attainment target documents, our participants are hypothesized to be moving towards more 
abstract thinking, learning the epistemological and methodological principles of the discipline, and applying them when answering questions on written tests and exams. They start to see the difference between popularized romanticized history, as it may be shown in movies or novels, and the structured and rational method to understand and interpret historical events. They learn the difference between recording, appraising, interpreting or judging historical events, figures and artifacts (Coffin, 2006, p. 158), and learn to see such artifacts as historical documents reflecting a certain zeitgeist and historical era.

\subsubsection{Writing in the mother tongue: what we expect of 15-year-old adolescents}

As regards writing in the mother tongue, students are expected "to write clearly, accurately and coherently, adapting their language and style in and for a range of contexts, purposes and audiences" (Department of Education, 2013, p. 2; VVKSO, 2012). "Pupils should continue to develop their knowledge of and skills in writing, refining their drafting skills and developing resilience to write at length. They should be taught to write formal and academic essays as well as writing imaginatively. They should be taught to write for a variety of purposes and audiences across a range of contexts. This requires an increasingly wide knowledge of vocabulary and grammar." (Department of Education, English Key Stage 3, p. 2) In Flemish curricular documents, it is also stated that students should learn to structure their texts logically, pay attention to functional and semantic relations and respect conventions relating to language and content, which points in the direction of beginning genre mastery, even if within mother tongue education, the genre addressed may not be the historical report.

\subsubsection{Writing in French: what we expect of 15-year-old adolescents}

In The Flemish Curriculum For French As A Foreign Language (VVSKO, 2012b), It Is Said That Students In The Second Grade Of Secondary Education Must Be Able To Describe A Situation, An Event Or An Experience In Texts That Have The Following Characteristics: Texts Concern A Concrete, Not An Abstract Subject That Is Familiar To Students And Is Taken From Their Own World And Daily Life. The Students Write Simple Sentences Or Simple Compound Sentences. There Is A Simple And Clear Text Structure And The Texts Are Fairly Short. The Vocabulary Is Sufficient To Write About Their Own Living Environment. Students Can Use Standard Language And Can Write In Both Informal And Formal Ways. In The Attainment Targets It Is Said That Student Should Be Able To Write A Brief Report Or Express Their Opinion In An Informative Text (VVKSO, 2012b, P. 47).

When Transposing This A2-Level For Writing In French To The Descriptors For Writing In History/Civics And Mathematics, Proposed By The Council Of Europe (2015), It Appears That Students Should Be Able To Do The Following In French Within The Context Of A CLIL Course:

- Write very short, basic descriptions of events and activities

- Explain how to do something or what has been done in a simple way

- Make brief statements about subject related issues

- Express in a simple way, what $s / h e$ thinks about something, or whether $s /$ he is for or against something

- Briefly and in a simple and basic way, give some reasons for what $\mathrm{s} / \mathrm{he}$ has done or will do in a subject related context.

- Pick out and reproduce key words and phrases or short sentences from a short text.

- Reproduce a definition for a mathematical or historical concept in a brief and simple way.

- Write a brief text copying a basic pattern.

- State whether something is good or bad, positive or negative in simple sentences

- Use simple descriptive language to make brief statements about and compare objects and alternatives.

- Put basic information into forms, lists or charts responding to subject tasks.

Thus, it can be seen that the attainment targets set for writing in French are low in view of the fact that our participants are expected to write in French about historical events in an objective historical narrative and appraise to what extent these historical events may be relevant for today's society.

\subsection{Systemic Functional Linguistics as the Essay Appraisal Framework}

What we needed to analyse students' history reports was a framework that would allow us to assess in an 
integrated way students' mastery of the contents of the history course on the one hand, and on the other their ability to write as a historian from a linguistic point of view. We found Michael Halliday's Systemic Functional Linguistics (SFL) Framewerk (Halliday \& Mathiessen, 2004), complemented with Martin and White's (2005) Evaluative language framework ideally fit for our purposes (also see Llinares \& Morton, 2017).

According to Halliday and Mathiessen (2004), three general types of functional meaning, namely ideational, interpersonal and textual, organize the language system and its utterances, such as written texts (Davidse et al 2020). Making use of the possibilities of a given language system, language users produce texts (textual function) to write about something (ideational meaning) and creating a particular interpersonal context (interpersonal function). The text produced may refer to other similar texts or genres and make use of typical conventions, or not (textual function), and it may involve the readership in different ways. For example, authors may merely want to inform their readers, but they may also want to appeal to them, entice them into doing something, manipulate their views regarding something, etc. (interpersonal function). Ideationally speaking, authors make choices regarding what topics to include or to leave out, how to organize their text, what topics to emphasize or connect in order to present their worldview.

Because of the presence of both an ideational, textual and interpersonal perspective, the SFL framework is ideally fit for analyzing student compositions written within the context of CLIL history education. In such compositions, students write a text that is supposed to meet particular textual and linguistic conventions (linguistic-textual function). They write about the world for a particular audience (linguistic-interpersonal function) and this writing about the world is co-determined by their mastery of the language they are using (ideational-linguistic function).

Because it was expected that our participants might not yet fully master the objectifying academic register, we completed Halliday's SFL Framework with insights from Martin and White (2005), who identified the cognitive-linguistic appraisal resources of the English language, such as words, collocations or expressions to express feelings, engagement or graduation, with the latter term referring to language that can be used to sharpen, weaken, soften, enlarging or decreasing (the importance of) a saying or message.

Given that historians are expected to use the objective register, it was determined that student texts should be void of such evaluative language. When writers express their moods, sense of engagement or graduation too strongly or explicitly, their report cannot be considered neutral or reflective of the recording historian. Moreover, their report should not focus on the individual's views as expressed in the here and now, but possess a degree of generality that is independent of context parameters (Council of Europe, 2016, p. 38). Texts written in academic discourse will use precise terminology, generic terms that reflect the discipline's concepts and theoretical frameworks, objectivized forms of location in time, appropriate conjunctions, complex sentences expressing relationships, etc. (p. 38).

\section{RESEARCH QUESTIONS}

Given the above, it was not easy to hypothesize about what the participants in our study would be able to do when confronted with an essay question to which they had to provide a well-structured historically-sound answer written in French and using an objectifying neutral register. Our expectation was that they might not yet have a full command of the academic objectifying register, given their age, but that they might nevertheless be able to write a coherent essay about the historical topic covered in class, realizing the textual, interpersonal and ideational functions of the text. As regards the mastery of the French language, we expected that it would hamper to quite some extent students' possibilities to express the voice of the historian in a neutral register.

Our research questions, then, were the following:

- Are 15-year-old Flemish adolescents taking a history course in French able to write a French-medium historical essay in response to a structured exam question?

- Are 15-year-old Flemish adolescents taking a history course in French as able as non-CLIL students of that age taking the same history course in their mother tongue to write a historical essay in response to an exam question?

\section{METHODOLOGY}

\subsection{Data Collection}

To investigate these questions, we collected essays written within the framework of the history exam from 
two CLIL classes $(\mathrm{N}=28)$ and one non-CLIL class $(\mathrm{N}=9)$ in general secondary education (Recour, 2021). All three classes were given an essay prompt containing three types of questions that historians usually ask themselves: 'What are the objective facts?', 'How can I interpret those facts?', 'How do I estimate the importance of the events?'. The students had to answer these question types with respect to the specific topic they had covered in class, which was either the Great Voyages of Discovery or Reformation and Counter Reformation.

An example prompt, translated from French into English, is given below in Fig. 1. From the example, it can be seen that the prompts wanted to investigate students' ability to describe, narrate and interpret historical events in an objective way and appraise and comment on their meaning, again demonstrating their command of academic objectifying discourse.

We covered the Great Voyages of Discovery during class.

- Who were the important figures? (describe, narrate facts)

- What do you think were the reasons for the voyages of discovery? Give at least two reasons (the most important ones) and explain why these are the most important reasons. (interpret facts)

- Would you say that the voyages of discovery were a good or a bad thing? Make a choice and give at least two reasons for your choice. (appraise, comment on historical events)"

Fig. 1: Example prompt

\subsection{Example Essay}

Exam prompts were offered in three classes, which yielded a corpus of 36 essays of varying length. In the CLIL-classes, students were asked to write in French to the best of their abilities. Yet, when a word slipped their mind, they were allowed to use a Dutch word to be able to continue and express their thinking.

An example essay and its translation into English are included below as Fig. 2 and Fig. 3.

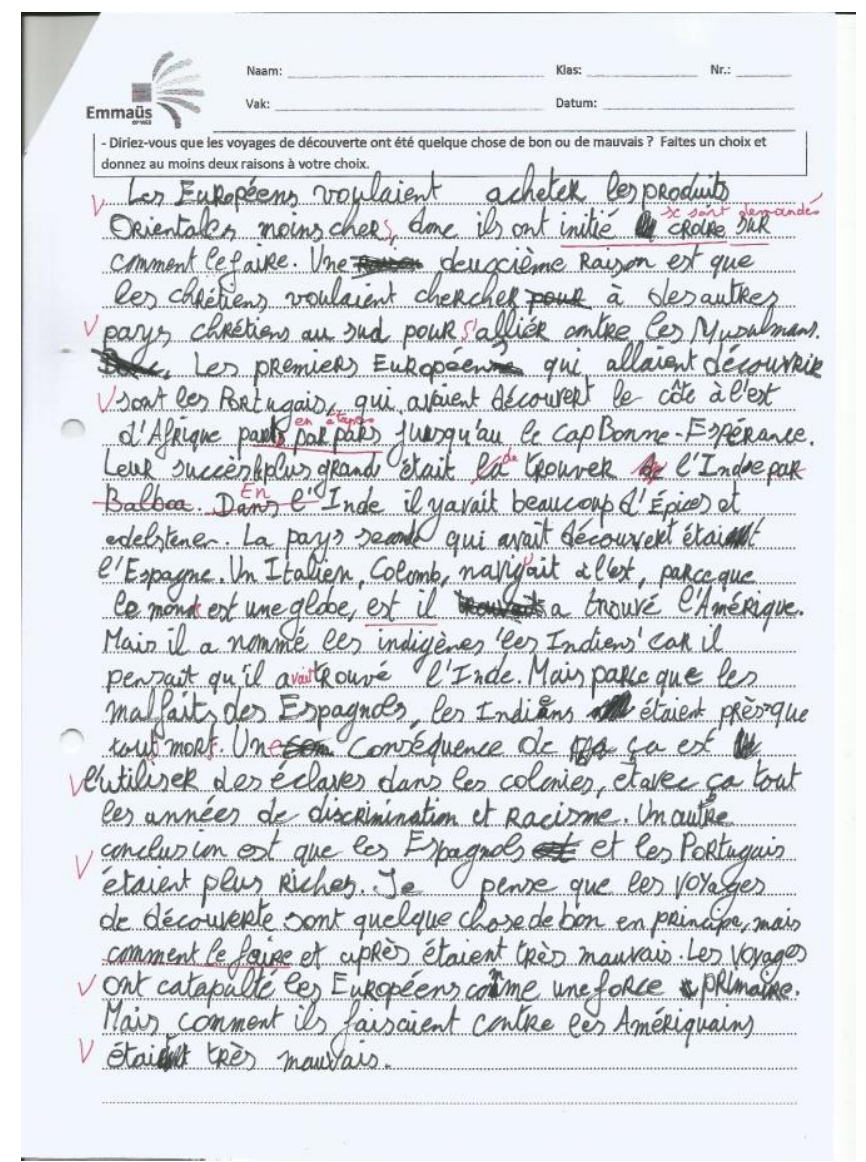

Fig. 2: Example student essay written in French 
"The Europeans wanted to buy oriental products cheaper, so they wondered how to do it. A second reason is that the Christians wanted to look for other countries to ally with to fight the Muslims.

The first Europeans to discover were the Portuguese, who had discovered the east coast of Africa in stages up to Cape Good Hope. Their greatest success was to find 'India. In India, there were many spices and precious stones.

The second country that was discovering was Spain. An Italian, Colomb, sailed east, because the world is a globe, and he found America. But he called the natives 'Indians' because he thought he had found India. But because of the crimes of the Spaniards, the Indians were almost all dead. One consequence of this is the use of slaves in the colonies, and with that all the years of discrimination and racism. Another conclusion is that the Spanish and Portuguese became richer.

I think that the voyages of discovery are something good in principle, but how they were done and what happened afterwards were very bad. The voyages catapulted the Europeans as a primary force. But what they did to the Americans was very bad."

Fig. 3: Translation of the student example essay

\subsection{Scheme for Analysis}

The essays were analyzed using the scheme presented in Table 1 below. A mark (/10) was assigned to each essay, representing the text's overall quality (A2-CEFR level or above put into practice in French, B1level put into practice in Dutch) and reflecting the text's overall success with respect to the command of the genre of the historical narrative, with 1 point assigned to overall text quality, 3 points assigned to 'voice of the historian', 3 to the level of success in putting into practice the textual, ideational and interpersonal functions of the historical narrative and 2 points for maintaining an objectifying discourse.

Table 1: Scheme used for the analysis of the student essays

\begin{tabular}{|c|c|c|c|}
\hline \multicolumn{2}{|c|}{ Assessment criteria } & \multirow[t]{2}{*}{$\mathrm{Y} / \mathrm{N}$} & \multirow[t]{2}{*}{ How it is said in the text } \\
\hline $\begin{array}{l}\text { Voice of the } \\
\text { historian }\end{array}$ & $\begin{array}{l}\text { Historian as objective recorder } \\
\text { of facts }\end{array}$ & & \\
\hline & Historian as interpreter & & \\
\hline & $\begin{array}{l}\text { Historian as appraiser, } \\
\text { evaluator, judge }\end{array}$ & & \\
\hline \multirow[t]{3}{*}{ Functions } & $\begin{array}{l}\text { Textual function (coherence, } \\
\text { relationships expressed in } \\
\text { language, specialized } \\
\text { vocabulary) }\end{array}$ & & \\
\hline & $\begin{array}{l}\text { Interpersonal function (reader } \\
\text { enticed, addressed) }\end{array}$ & & \\
\hline & $\begin{array}{l}\text { Ideational function (worldview } \\
\text { presented) }\end{array}$ & & \\
\hline \multirow[t]{3}{*}{ Attitude } & $\begin{array}{l}\text { Emotions (expression of } \\
\text { feelings) }\end{array}$ & & \\
\hline & $\begin{array}{l}\text { Ethics (good/bad from ethical } \\
\text { perspective) }\end{array}$ & & \\
\hline & $\begin{array}{l}\text { Aesthetics (expression of } \\
\text { beauty) }\end{array}$ & & \\
\hline \multirow[t]{3}{*}{ Engagement } & Focus on personal views & & \\
\hline & Focus on others' views & & \\
\hline & Agreement with others' views & & \\
\hline
\end{tabular}




\begin{tabular}{|l|l|l|l|}
\hline & $\begin{array}{l}\text { Disagreement, lack of } \\
\text { compliance with others' views }\end{array}$ & & \\
\hline Graduation & Sharpening of message & & \\
\hline & Weakening of message & & \\
\hline & Enlarging of facts, events & & \\
\hline & Diminishing of facts, events, $\ldots$ & & \\
\hline
\end{tabular}

When analyzing the example text, we can note the following:

The student is largely able to use the voice of a historian.

- The student is able to describe and narrate historical events and facts in answer to the exam prompt, even if briefly.

- The student is able to interpret some of the facts and provide reasons for the Great Voyages of Discovery.

- Finally, we can see that the student appraises the historical events. Even if using a personal tone and focusing on his proper opinions, we can see that the reasons given are not merely personal reasons. The ground relate to the historical period described, and can thus be said to be reflect an understanding of the historical period and its consequences.

The student is almost able to express the textual, ideational and interpersonal functions of texts in his essay.

- In terms of text organization, there is room for improvement since the paragraphs do not always follow each other in a logical way. Yet, the text shows some internal coherence, uses important linking words expressing interrelationships between content elements, and uses the specialized language related to the topic at hand. Thus, it shows some characteristics of the genre "historical report.

- When looking into the ideational function of the text, it is interesting to see that the student presents the historical era from different perspectives: that of the discoverers, that of the indigenous people, that of the slaves, that of the Muslims and the Christians. It is likewise notable that different societal domains are touched upon in the text and are shown in interactions. There is the economic-commercial domain, the religious domain en the societal domain. Finally, the student is able to reflect on what the era meant in the long-term, for example through establishing Europe as a rich country and a world-power.

- As regards the interpersonal function, the student combines an overall objectifying academic discourse, explaining to the readership what is known about the era in focus, with a more personal style of writing when explaining what he believes to be the importance of what happened during the age of the Great Voyages of Discovery for today's society. Thus, as an appraiser of history, which is one of the voices of the historian distinguished by Coffin (2006), the student establishes a more personal and perhaps more tentative relationship with the readership (I think). The following examples show that the student uses evaluative language at times, which diminishes the neutral tone expected of the genre. These words include: 'le plus grand succès' (the biggest success), 'les malfaits' (the crimes), 'discrimination et racisme' (discrimination and racism), 'quelque chose de bon' (something good), 'très mauvais' (very bad), 'catapulté' (catapulted), 'très mauvais' (very bad).

All in all, we can conclude that this student is able to write with the voice of a historian and to realize the textual, ideational and interpersonal functions of texts above the expected level of ability, given his age and the fact that no more than A2-CEFR-level of writing skills is expected at his level of education.

We now proceed to presenting the results for all 36 student essays.

\section{RESULTS}

\subsection{Voice of the Historian}

Of the 36 essays $32(89 \%)$ demonstrate the students' ability to describe and narrate historical facts. As regards the interpretation of facts, 25 out of 36 or $69 \%$ of students can interpret historical facts and infer meaning from them. Given that students had to choose what facts to narrate and what interpretations to give, 
one could say that students' can function as author-historians (Coffin, 2006), who can take a position and express certain evaluation or judgement. $89 \%$ of students could also consider some implications of the facts they narrated for today's society, writing for example that "one could say that the great voyages of discovery were not black or white, but something grey, something in between."

\subsection{Textual, Ideational and Interpersonal Functions of Texts}

With respect to the textual function, it appears that almost all students were able to write the type of text expected of them in answer to an exam prompt asking them to name historical facts, interpret them and reflect on their meaning for today's society. Those who could not were those who appeared not to have studied enough for the exam. The extent to which they could do so varied, with some texts merely enumerating bullet points, and others equaling well-structured coherent historical reports.

All students could use some of the specialized vocabulary related to the historical topic at hand, yet not all students were able to use an objective register, with some students merely interpreting historical facts in terms of their own personal experiences, making statements, such as "I do not like this because ..." or "I think it is positive that people like Luther or Calvin protested against the church."

The linking words most frequently used are 'et' (and), 'parce que' (because), and 'donc' (consequently) or synonyms thereof. They were used by 31 out of 36 students. The other five students merely listed sentences or bullet points and made no effort to link them into a coherent text or establish interrelations between sentences.

The interpersonal function appears the most difficult one to convert into practice. Students often start writing in an objective manner and using objectifying academic discourse, yet, towards the end of their essays and when asked to assess the implications of the historical events for today's society, they tend to switch to a more personalized voice, centering on their own opinions and trying to engage the reader to agree with them. Thus, they can write things, such as "la predestination est ridicule" (predestination is ridiculous) or "I think that the evolution of religions is very positive", when writing about Reformation and Counter Reformation. Another student wrote "Je suis heureux que je suis né au 21 ième siècle parce que le 16ième siècle semble un peu plus dangereux pour moi" (I am happy I was born in the $21^{\text {st }}$ century because the $16^{\text {th }}$ century appears more dangerous to me). As a matter of fact, $72 \%$ of students (26 out of 36 ) used this type of personal, not historically substantiated expressions explicitly at least once in their compositions. The introductory phrase used most frequently is "je pense", which can be translated as 'I think' or 'I believe'.

Graduation, expressed most frequently by the use of words, such as 'le plus' (for expressing superlative, such as 'the most important), 'très' (very) or 'beaucoup' (a lot (of)), is overly present in student essays, with only one student writing exclusively in the objective historian voice, leaving out all graduating, feeling, or engaging language.

\subsection{CLIL-Students versus Non-CLIL Students: Scores Obtained}

The mean score assigned was $7 / 10$, with marks ranging between $5 / 10$ and $8 / 10$. The example text was assigned a score of 7,5/10.

The CLIL-group of students reached an average score of 7.3/10, whereas the non-CLIL students who could write in Dutch achieved an average score of 6.8/10, which suggests that CLIL-learners on average can deliver a better historical text if we analyze those texts within our framework and do not punish students for not mastering the French language up to a more flawless B1 level.

\section{DISCUSSION}

The overall aim of the study was to shed light on the extent to which 15-year-old students in CLIL-historyFrench courses in secondary education in Flanders are able to write as historians when prompted with an exam question inquiring into their ability to describe and narrate historical facts, interpret those facts and assign meaning to them within the historical era when they took place and reflect on them from the point of view of what they have meant for today's society.

The findings suggest that CLIL-students are slightly better at expressing themselves like historians would do than non-CLIL students, at least when students are not punished for making linguistic mistakes, and accepting the texts as a proficient text when the text is fully comprehensible despite some lexicogrammatical flaws.

The most striking finding was that, overall, CLIL-students do as well or better than non-CLIL-students, despite the fact that they are studying a complex subject, such as history, in a foreign language. One of the 
reasons for this may be that CLIL-students are self-selected high achievers, and that their academic talents, cognitive intelligence, and study motivation also become apparent in history courses, where they are expected to acquire the objectifying voice of a historian, empathize with other cultures and eras, and connect historical events to today's society. Yet, in the non-CLIL group, some students also demonstrated an equally high mastery of the subject matter and command of the objectifying academic register. The question then is whether students' mastery of the language (Dutch as a mother tongue versus French as a foreign language) is the main factor to consider when studying the level of mastery of a particular subject in CLIL education, as tends to have been done in research to date. As our study shows, some CLIL- and non-CLIL students are able to master the subject matter up to the level expected of them at their developmental age, whereas other students, CLIL- and non-CLIL are not. Some pupils may want to express their personal opinions, in an attempt to define their own identity as young adults, not realizing yet that this is not appropriate when writing an answer to an exam question or writing a historical report. The expectation is though that, as their brain matures and as they grow older and more adult-like, they too may acquire a better command of the academic register, given that many of them may opt to take on further studies in higher education or at the university level.

A second striking finding was the quite high level of mastery of the French language in the CLIL-classes. On the basis of the lessons taught, these pupils are able to produce linguistic messages in French of which the linguistic proficiency level is close to a (beginning) B1 level, which is normally the level of writing expected at the end of secondary education. Students demonstrate that they can build well-formed sentences and use a large variety of vocabulary, even if grammatical and spelling mistakes may still be frequent. Overall, they do not hinder the understanding of the text. Using the type of exam prompts that we used, making a clear distinction between questions asking students to report on facts, interpret facts or reflect on the meaning of facts for today's society, appears to have helped students to surmount the added difficulties of having to write an essay in French. Also, it appears that the 4-hour CLIL-curriculum, which is the maximum number of school periods allowed for CLIL-education in Flanders (Strobbe \& Sercu, 2010; Strobbe et al., 2013), together with the 3 hours of regular French teaching, suffice to promote a French-thinking mindset in these students, boost their confidence to use the foreign language, even when writing about historical topics. In Flanders, students have started to learn French from the age of 10 onwards, with a very limited number of hours per week at first, but with 3 hours of French per week during the $1^{\text {st }}, 2^{\text {nd }}, 3^{\text {rd }}$ and $4^{\text {th }}$ year of general secondary education.

Even if the well-structured prompts aimed to elicit students' objectifying academic discourse, we had expected to see more outspoken subjective interpretations, especially in answer to the third part of each prompt, namely where the student is asked to reflect on the meaning of the historical facts for today's society. Though many students are not able to fully surpass the purely personal level, that is more typical of younger students, other students clearly demonstrate the capacity to substantiate their arguments with facts and insightful observations. We believe this may be due to the excellent teaching skills of the teachers involved in our study. The teachers self-selected for the study on the basis of a brief description of what the project would involve. Further research will show to what extent our results are replicable when data are collected in randomly selected classes or schools.

Though the sample for this qualitative study was small, we believe we have been able to show tendencies which deserve further investigation. The results underline the beneficial effects that can arise from CLILeducation also with respect to the perhaps more accelerated mastery of academic discourse. It will be interesting to see how the students involved in this study keep evolving and where CLIL-history education will get them towards the end of secondary education. In this respect, it would be interesting to study what effect explicit teaching in how to write like a historian might bring them. All of this can be done when teachers are knowledgeable about the genre of the historical report and know how to teach its characteristics. Using Halliday's Systemic Functional Linguistic Framework (Halliday \& Matthiessen, 2014)) together with the 'language of evaluation' framework of Martin and White (2005), a professional training program could be set up that might clarify both a genre's content characteristics as well as what language can be used to produce a text that meets the genre's conventions. Such a course may be useful for CLIL and non-CLIL teachers alike, and not only for those who teach history, but also for teachers of other subjects (e.g., Social Studies, Cultural Studies or Civics). Understanding the different learning tasks involved in writing like a historian or a social scientist may help teachers to reconsider assessment practices in CLIL education and opt for truly integrative approaches that assess both content-and-language in an integrated way.

\section{CONCLUSION}

This small-scale qualitative study on the acquisition of the voice of the historian in general secondary 
education in two CLIL history French classrooms and one non-CLIL history classroom in Flanders highlights the need to consider CLIL performance on a history exam as a complex interaction between language and content mastery. Awareness and understanding of this interaction can support both teachers and learners in their approach to CLIL education. Together with a focus on the acquisition of subject matter contents, CLIL pedagogy can deepen its focus on the mastery of genre characteristics and the language needed to command these genres in a foreign language. In this way, CLIL education will become truly integrative, granting equal importance to language and subject matter learning.

We hope this research may inform researchers involved in the comparison of CLIL- versus non-CLILeducation, especially from the point of view of subject matter learning and the acquisition of academic discourse. We believe that the analytic scheme we have proposed is fit for the integrated evaluation of students' content-and-language performance, even if it can be further refined. We also hope, it may inform teachers about how to assess their learners and support them in developing their academic writing skills, within the discipline of history but also of within other sciences.

\section{REFERENCE LIST}

Davidse, K., Van Praet, W., \& Njende, N.M. (2019). Introduction: communicative dynamism. Acta linguistica hafniensia, 51(2), 107-123. https://doi.org/10.1080/03740463.2019.1695242

Department of Education (2013). History Programme of Study Key Stage 3. Crown.

Council of Europe (2015). Language skills for successful subject learning. CEFR-linked descriptors for mathematics and history/civics. Available at www.ecml.at

Council of Europe (2016). A handbook for curriculum development and teacher training. The language dimension in all subjects. Available at www.ecml.at

Halliday, M.A.K., Matthiessen, C. (2004). An introduction to functional grammar. 3rd ed. Edward Arnold.

Llinares, A., \& Morton, T. (2017). Applied linguistics perspectives on CLIL (Vol. 47). John Benjamins Publishing Company.

Martin, J., White, P.R.R. (2007). The Language of evaluation: Appraisal in English. Palgrave Macmillan UK. https://doi.org/10.1057/9780230511910

Ofqual (2020) GCSE Subject Level Conditions and Requirements for History (2021). Ofqual.

Pavon Vazquez, V. (2018). Innovations and Challenges in CLIL Research: Exploring the Development of Subject-Specific Literacies. Theory into practice, 57(3), 204-211. https://doi.org/10.1080/00405841.2018.1484035

Recour, J. (2021). 'Pendant les cours d'histoire, j'apprends le français aussi.' De ontwikkeling van de voice of the historian tijdens CLIL-lessen geschiedenis. Een onderzoek onder Vlaamse leerlingen (Master thesis). KU Leuven: Faculteit Letteren.

Sercu, L., \& Strobbe, L. (2010). Geïntegreerd taal- en zaakvakonderwijs in het 9-voud. Een voorlopige balans van 3 proeftuinjaren. Impuls voor Onderwijsbegeleiding, 4, 147-155.

Strobbe, L., Sercu, L., \& Strobbe, J. (2013). Je vak in een vreemde taal?: wegwijzer voor de CLILonderwijspraktijk. Acco.

VVKSO (1999) Leerplan Geschiedenis. Aso. $2^{\text {de }}$ graad. VVKSO.

VVKSO (2012) Leerplan Nederlands. Aso. $2^{\text {de }}$ graad. VVKSO.

VVKSO (2012b) Leerplan Frans. Aso. 2de graad. VVKSO.

\section{ACKNOWLEDGEMENTS}

The author would like to thank Julie Recour for her assistance in data collection and analysis, as well as the teachers and student who participated in the study. 
Proceedings of SOCIOINT 2021 8th International Conference on Education and Education of Social Sciences 14-15 June, 2021

\section{DECLARATION OF CONFLICTING INTERESTS}

The author declares no potential conflict of interest.

\section{FUNDING}

The author received no financial support for the research. 